\title{
GAMBARAN TINGKAT KEPUASAN PASIEN TERHADAP PELAYANAN INFORMASI OBAT DI APOTEK RAWAT JALAN RSUD LABUANG BAJI MAKASSAR
}

\author{
A.Suparlan Isya Syamsu, Farida \\ Sekolah Tinggi Ilmu Kesehatan Mega Rezky Makassar \\ Email : parlan.pance@gmail.com
}

\begin{abstract}
The research is conducted to determine the satisfaction level of patients of drug information service at pharmacy of Makassar Labuang Baji Hospital. This research used descriptive method using primary data by distributing questionnaires filled by the respondents. Data was collected by distributing questionnaires to 42 respondents who were outpatients. The questionnaire has five dimensions they are responsiveness, accurance / guarantee or assurance, empathy, reliability, tangible. Each dimension has three questions regarding drug information service conducted pharmacists in Makassar Labuang Baji Hospital. The research result is the highest patient satisfaction with the drug information service is the responsiveness and empathy dimension concern with the gained of the patient (98\%) and the lowest patient satisfaction with the drug information service is the Reability / reliability dimension with the gained of $86 \%$. Based on the questionnaire result can be concluded that the level of patient satisfaction with the drug information service in pharmacies of Makassar Labuang baji Hospital is largely satisfied as much as 96.4\%. It is hoped Makassar Labuang Baji Hospital to retain and keep improving the quality of drug information services so it can be an example for other hospitals as well.
\end{abstract}

Key words : Patients' satisfaction level, drug information service, Labuang Baji Hospital

\section{PENDAHULUAN}

Dewasa ini masalah kesehatan telah menjadi kebutuhan pokok bagi masyarakat. Dengan meningkatnya taraf hidup masyarakat, maka semakin meningkat pula tuntutan masyarakat akan kualitas kesehatan. Hal ini menuntut penyedia jasa pelayanan kesehatan seperti rumah sakit untuk meningkatkan kualitas pelayanan yang lebih baik, tidak hanya pelayanan yang bersifat penyembuhan penyakit tetapi juga mencakup pelayanan yang bersifat pencegahan (preventif) untuk meningkatkan kualitas hidup serta memberikan kepuasan bagi konsumen selaku pengguna jasa kesehatan (Anonim, 2004). Belum semua pasien tahu dan sadar akan 
Gambaran tingkat kepuasan pasien terhadap pelayanan informasi obat Di Apotek Rawat Jalan RSUD Labuang Baji Makassar

apa yang harus dilakukan tentang obat-obatnya, oleh sebab itu untuk mencegah kesalahgunaan, penyalahgunaan, dan adanya interaksi obat yang tidak dikehendaki, pelayanan infomasi obat dirasakan sangat diperlukan, terlebih lagi belum semua pasien mendapatkan informasi yang memadai dan juga pengetahuan tentang obat yang digunakan belum semuanya diketahui, apalagi adanya obat-obat tertentu yang sangat memerlukan perhatian. Disamping itu para pengelola dan pengguna obat, dalam hal ini farmasis tidak mempunyai cukup waktu untuk dapat menguasai dengan baik seluruh informasi obat yang beredar, sehingga tidak jarang terjadi pertentangan pendapat suatu obat (Ikasari, 2008).

Rumah sakit sebagai salah satu tempat pelayanan kesehatan terutama rumah sakit pemerintah harus dapat menjadi sarana kesehatan bagi masyarakat luas. Pelayanan kesehatan yang diberikan harus berkualitas agar memuaskan masyarakat sebagai konsumen. Pelayanan kesehatan yang bermutu adalah pelayanan kesehatan yang dapat memuaskan setiap pemakai jasa pelayanan sesuai dengan tingkat kepuasan rata-rata penduduk serta penyelenggaraannya sesuai dengan kode etik dan standar pelayanan yang telah ditetapkan.

Dasar pertimbangan kepuasan pasien adalah kesesuaian antara biaya yang dikeluarkan pasien terhadap barang dan jasa yang diperolehnya ada sebesar bukti yang menunjukan bahwa pasien sering tidak puas dengan jumlah informasi yang mereka terima dari tenaga kesehatan. Seluruh bukti menunjukan bahwa rata-rata $35 \%-40 \%$ tidak puas mengenai komunikasi dengan dokter mereka. (Lidya. 2010)

Pada penelitian sebelumnya yang di lakukan oleh Harianto di Jakarta pada tahun 2005 dengan judul "Kepuasan pasien terhadap pelayanan resep di apotek Kopkar rumah sakit budhi asih Jakarta". Pasien apotek Kopkar sangat puas terhadap keramahan petugas, dan kebersihan ruang tunggu, pasien juga cukup puas terhadap kecepatan pelayanan obat, kecepatan pelayanan kasir, kelengkapan informasi obat, kemurahan pelayanan obat, kecukupan tempat duduk, dan kenyamanan ruang tunggu dan kipas angin dan $\mathrm{AC}$, dan pasien cukup puas terhadap ketersediaan televisi (Harianto dkk, 2005).

Fenomena yang terjadi di instalasi farmasi RSUD labuang baji 
Gambaran tingkat kepuasan pasien terhadap pelayanan informasi obat Di Apotek Rawat Jalan RSUD Labuang Baji Makassar

Makassar khususnya pasien rawat jalan terlihat masih banyak pasien yang mendapatkan obat dengan jumlah yang banyak sehingga interaksi dan efek samping yang muncul menjadi lebih besar diakibatkan karna kurangnya pemahaman pasien terhadap obat. Sehingga dibutuhkan pelayanan informasi obat yang jelas tentang penggunaan obat yang harus dikonsomsi pasien.

Pelayanan informasi obat dari Apoteker kepada Pasien belum maksimal dikarenakan waktu pelayanan informasi obat yang terbatas dan informasi obat yang diberikan tidak menjelaskan semua hal tentang obat yang digunakan oleh pasien.

\section{METODE PENELITIAN}

\section{Jenis Penelitian}

Penelitian ini di lakukan dengan menggunakan desain cross sectional merupakan suatu penelitian mempelajari dinamika korelasi termasuk faktor resiko dengan efek, dengan cara pendekatan observasi atau pengumpulan data sekaligus pada suatu saat (point time apporoach)

\section{Populasi dan Sampel}

\section{Populasi}

Pada penelitian ini yang menjadi populasi adalah semua pasien yang menebus resep di apotek rawat jalan RSUD Labuang Baji Makassar.

\section{Sampel}

Sampel pada penelitian ini adalah kuesioner yang di sebarkan kepada pasien yang menyelesaikan administrasi untuk menebus resep di apotek rawat jalan RSUD Labuang Baji Makassar.

\section{Teknik Sampling}

Penelitian ini menggunakan metode accidental sampling, yaitu dilakukan dengan pengambilan respoden yang kebetulan ada atau tersedia di suatu tempat sesuai dengan konteks penelitian.

\section{Teknik Pengambilan Data}

Data yang digunakan adalah data primer yaitu data yang hanya di peroleh langsung dari sumber aslinya atau pe rtama, dan teknik pengumpulan data dalam penelitian ini adalah dengan cara mengumpulkan data dengan daftar beberapa pertanyaan melalui kuesioner yang di berikan kepada pasien rawat jalan yang menebus resep di instalasi farmasi RSUD Labuang Baji Makassar. Jumlah pertanyaan yang akan di berikan sebanyak 15 pertanyaan, setiap skala guttman masing-masing memiliki pertanyaan 
Gambaran tingkat kepuasan pasien terhadap pelayanan informasi obat Di Apotek Rawat Jalan RSUD Labuang Baji Makassar

yaitu ketanggapan tiga pertanyaan, jaminan atau kepastian tiga pertanyaan, empati tiga pertnyaan, keandalan tiga pertnyaan, berwujud tiga pertanyaan.

\section{Analisis Data}

Analisis data yang digunakan secara univariat dianalisiskan secara deskriptif melalui frekuensi dan distribusi yang di uraikan dalam prosentase untuk memberikan gambaran umum.

Dengan menggunakan rumus :

Tabel. 1. Data Karakteristik Responden
$\mathrm{P}=\frac{f}{N} X 100 \%$

Dimana:

$\mathrm{P}=$ Presentase yang di cari $\mathrm{F}=$ Jumlah pengamatan (observasi )

$\mathrm{N}=$ Jumlah sampel (populasi )

\section{HASIL PENELITIAN}

Berdasarkan hasil penelitian 42 orang pasien di apotek rawat jalan RSUD Labuang Baji Makassar maka di proleh hasil penelitian tentang gambaran tingkat kepuasan pasien di apotek rawat jalan RSUD Labuang Baji Makassar sebagai berikut:

\begin{tabular}{|c|c|c|c|}
\hline No & Variabel & Jumlah & $\%$ \\
\hline \multirow{5}{*}{1} & Umur & & \\
\hline & a. Remaja : 13-17 tahun & 1 & $2,5 \%$ \\
\hline & b. Dewasa : 18-49 tahun & 19 & $45 \%$ \\
\hline & c. Orang tua : 50 tahun keatas & 22 & $52,5 \%$ \\
\hline & Jumlah & 42 & $100 \%$ \\
\hline \multirow{4}{*}{2} & Jenis Kelamin & & \\
\hline & a. Laki-laki & 17 & $40 \%$ \\
\hline & b. Perempuan & 25 & $60 \%$ \\
\hline & Jumlah & 42 & $100 \%$ \\
\hline \multirow{7}{*}{3} & Pendidikan & & \\
\hline & a. Tidak tamat SD & 0 & $0 \%$ \\
\hline & b. SD & 3 & $7 \%$ \\
\hline & c. SMP & 5 & $12 \%$ \\
\hline & d. SMA & 12 & $29 \%$ \\
\hline & e. Perguruan Tinggi / Akademi & 22 & $52 \%$ \\
\hline & Jumlah & 42 & $100 \%$ \\
\hline \multirow{8}{*}{4} & Pekerjaan & & \\
\hline & a. Mahasiswa/mahasiswi & 9 & $21 \%$ \\
\hline & b. Wiraswasta & 3 & $7 \%$ \\
\hline & c. Pegawai negri sipil & 8 & $19 \%$ \\
\hline & d. Pegawai swasta & 4 & $10 \%$ \\
\hline & e. Ibu rumah tangga & 15 & $36 \%$ \\
\hline & f. Lain-lain & 3 & $7 \%$ \\
\hline & Jumlah & 42 & $100 \%$ \\
\hline
\end{tabular}

Dari data di atas dapat di tarik kesimpulan sebagian besar responden berusia 50 tahun keatas dan berpendidikan perguruan tinggi 
Gambaran tingkat kepuasan pasien terhadap pelayanan informasi obat Di Apotek Rawat Jalan RSUD Labuang Baji Makassar

sejumlah 22 Orang $(52,5 \%)$ dan untuk jenis kelamin sebagian besar responden berjenis kelamin perempuaan sebanyak 25 orang
(60\%). Sementara untuk pekerjaan sebagian besar responden adalah bekerja sebagai ibu rumah tanggga sebanyak 15 orang (36\%).

Tabel 2. Tanggapan responden terhadap dimensi responsivenees/daya tanggap

\begin{tabular}{|c|c|c|c|c|c|}
\hline \multirow{3}{*}{ No } & \multirow{3}{*}{ Daftar pertanyaan } & \multicolumn{4}{|c|}{ Tingkat kepuasan } \\
\hline & & \multicolumn{2}{|c|}{ Puas } & \multicolumn{2}{|c|}{ Tidak puas } \\
\hline & & $\mathbf{n}$ & $\%$ & $\mathbf{n}$ & $\%$ \\
\hline 1. & Petugas cepat terhadap keluhan pasien & 40 & $95 \%$ & 2 & $5 \%$ \\
\hline 2. & $\begin{array}{l}\text { Petugas mampu memberikan penyelesaian } \\
\text { terhadap masalah vana di hadapi pasien }\end{array}$ & 41 & $98 \%$ & 1 & $2 \%$ \\
\hline 3. & $\begin{array}{l}\text { Terjadi komunikasi yang baik antara petugas } \\
\text { dan pasien }\end{array}$ & 42 & $100 \%$ & - & - \\
\hline & Rata-rata & 41 & $98 \%$ & 1 & $2 \%$ \\
\hline
\end{tabular}

Sumber : Data primer 2015

Dari data di atas dapat di tarik kesimpulan sebagian besar responden berusia 50 tahun keatas dan berpendidikan perguruan tinggi sejumlah 22 Orang $(52,5 \%)$ dan untuk jenis kelamin sebagian besar responden berjenis kelamin perempuaan sebanyak 25 orang (60\%). Sementara untuk pekerjaan sebagian besar responden adalah bekerja sebagai ibu rumah tanggga sebanyak 15 orang (36\%).

Tabel 3. Tanggapan responden terhadap dimensi assurance/ jaminan

\begin{tabular}{|c|c|c|c|c|c|}
\hline \multirow{3}{*}{ No } & \multirow{3}{*}{ Daftar pertanyaan } & \multicolumn{4}{|c|}{ Tingkat kepuasan } \\
\hline & & \multicolumn{2}{|c|}{ Puas } & \multicolumn{2}{|c|}{ Tidak puas } \\
\hline & & $\mathbf{n}$ & $\%$ & $\mathbf{n}$ & $\%$ \\
\hline 1. & $\begin{array}{l}\text { Petugas mempunyai keterampilan yang baik } \\
\text { dalam bekerja. }\end{array}$ & 40 & $95 \%$ & 2 & $5 \%$ \\
\hline 2. & Komunikasi yang efektif dengan pasien. & 40 & 95 & 2 & $5 \%$ \\
\hline 3. & Obat yang di beli terjamin kualitasnya & 41 & $98 \%$ & 1 & $2 \%$ \\
\hline & Rata-rata & 40 & $96 \%$ & 2 & $4 \%$ \\
\hline
\end{tabular}

Sumber : Data primer 2015

Berdasarkan gambaran dari tabel responsivenees/daya tanggap di atas menunjukan sebagian besar pasiennya menyatakan puas 41 orang (98\%). 
Gambaran tingkat kepuasan pasien terhadap pelayanan informasi obat Di Apotek Rawat Jalan RSUD Labuang Baji Makassar

Tabel 3. Tanggapan responden terhadap dimensi assurance/ jaminan

\begin{tabular}{|c|c|c|c|c|c|}
\hline \multirow{3}{*}{ No } & \multirow{3}{*}{ Daftar pertanyaan } & \multicolumn{4}{|c|}{ Tingkat kepuasan } \\
\hline & & \multicolumn{2}{|c|}{ Puas } & \multicolumn{2}{|c|}{ Tidak puas } \\
\hline & & $\mathbf{n}$ & $\%$ & $\mathbf{n}$ & $\%$ \\
\hline 1. & $\begin{array}{l}\text { Petugas mempunyai keterampilan yang baik } \\
\text { dalam bekeria. }\end{array}$ & 40 & $95 \%$ & 2 & $5 \%$ \\
\hline 2. & Komunikasi yang efektif dengan pasien. & 40 & $95 \%$ & 2 & $5 \%$ \\
\hline 3. & Obat yang di beli terjamin kualitasnya. & 41 & $98 \%$ & 1 & $2 \%$ \\
\hline & Rata-rata & 40 & $96 \%$ & 2 & $4 \%$ \\
\hline
\end{tabular}

Sumber : Data primer 2015

Berdasarkan gambaran dari pasiennya menyatakan puas 40 orang tabel assurance/ jaminan di atas (96\%).

menunjukan sebagian besar

Tabel 4. Tanggapan responden terhadap dimensi Empathy/ empaty

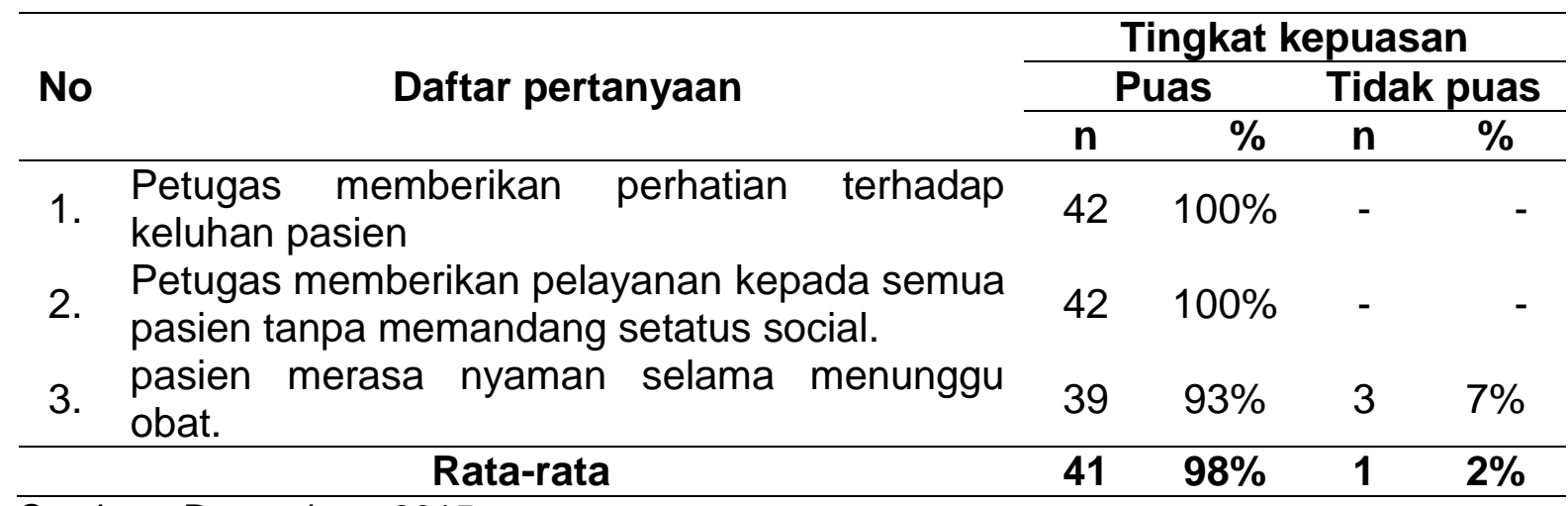

Sumber : Data primer 2015

Berdasarkan gambaran dari pasiennya menyatakan puas 41 orang tabel empathy/ kepedulian di atas (98\%).

menunjukan sebagian besar

Tabel 5. Tanggapan responden terhadap dimensi reability/ keandalan

\begin{tabular}{|c|c|c|c|c|c|c|}
\hline \multirow{3}{*}{ No } & \multirow{3}{*}{\multicolumn{2}{|c|}{ Daftar pertanyaan }} & \multicolumn{4}{|c|}{ Tingkat kepuasan } \\
\hline & & & \multicolumn{2}{|c|}{ Puas } & \multicolumn{2}{|c|}{ Tidak puas } \\
\hline & & & $\mathbf{n}$ & $\%$ & $\mathbf{n}$ & $\%$ \\
\hline 1. & Kecepatan pelay & & 38 & $90 \%$ & 4 & $10 \%$ \\
\hline 2. & Obat yang tersedia dengan lengkap. & & 31 & $74 \%$ & 11 & $26 \%$ \\
\hline 3. & $\begin{array}{l}\text { Petugas melayani dengan } \\
\text { tersenyum. }\end{array}$ & dan & 39 & $93 \%$ & 3 & $7 \%$ \\
\hline & Rata-rata & & 36 & $86 \%$ & 6 & $14 \%$ \\
\hline
\end{tabular}

Sumber : Data primer 2015 
Gambaran tingkat kepuasan pasien terhadap pelayanan informasi obat Di Apotek Rawat Jalan RSUD Labuang Baji Makassar

Berdasarkan gambaran dari tabel reability/ keandalan di atas menunjukan sebagian besar pasiennya menyatakan puas 36 orang (86\%).

Tabel 6. Tangapan responden terhadap dimensi tangibles/wujud nyata

\begin{tabular}{|c|c|c|c|c|c|}
\hline \multirow{3}{*}{ No } & \multirow{3}{*}{ Daftar pertanyaan } & \multicolumn{4}{|c|}{ Tingkat kepuasan } \\
\hline & & \multicolumn{2}{|c|}{ Puas } & \multicolumn{2}{|c|}{ Tidak puas } \\
\hline & & $\mathbf{n}$ & $\%$ & $\mathbf{n}$ & $\%$ \\
\hline 1. & Apotek terlihat bersih dan rapi. & 40 & $95 \%$ & 2 & $5 \%$ \\
\hline 2. & $\begin{array}{l}\text { Kelengkapan,kesiapan dan kebersian alat-alat } \\
\text { yang di pakai }\end{array}$ & 40 & $95 \%$ & 2 & $5 \%$ \\
\hline 3. & $\begin{array}{l}\text { Petugas apotek berpakaian yang bersih dan } \\
\text { rapih. }\end{array}$ & 41 & $98 \%$ & 1 & $2 \%$ \\
\hline & Rata-rata & 40 & $96 \%$ & 2 & $4 \%$ \\
\hline
\end{tabular}

Sumber : Data primer 2015

Gambaran dari tabel tengibles/

wujud nyata di atas menunjukan sebagian

besar

pasiennya menyatakan puas 40 orang (96\%).

Tabel 7. Hasil kuesioner gambaran tingkat kepuasan pasien terhadap pelayanan informasi obat di apotek rawat jalan RSUD Labuang Baji Makassar

\begin{tabular}{|c|c|c|c|c|c|}
\hline \multirow{3}{*}{ No } & \multirow{3}{*}{ Pertanyaan } & \multicolumn{4}{|c|}{ Tingkat kepuasan } \\
\hline & & \multicolumn{2}{|c|}{ Puas } & \multicolumn{2}{|c|}{ Tidak puas } \\
\hline & & $\mathbf{n}$ & $\%$ & $\mathbf{n}$ & $\%$ \\
\hline 1. & Petugas cepat terhadap keluhan pasien & 40 & $95 \%$ & 2 & $5 \%$ \\
\hline 2. & $\begin{array}{l}\text { Petugas mampu memberikan penyelesaian } \\
\text { terhadap masalah yang di hadapi pasien }\end{array}$ & 41 & $98 \%$ & 1 & $2 \%$ \\
\hline 3. & $\begin{array}{l}\text { Terjadi komunikasi yang baik antara petugas } \\
\text { dan pasien }\end{array}$ & 42 & $100 \%$ & & - \\
\hline 4. & $\begin{array}{l}\text { Petugas mempunyai keterampilan yang baik } \\
\text { dalam bekerja. }\end{array}$ & 40 & $95 \%$ & 2 & $5 \%$ \\
\hline 5. & ikasi yang efektif dengan pasien. & 40 & $95 \%$ & 2 & $5 \%$ \\
\hline 6. & ang di beli terjamin kualitasnya. & 41 & $98 \%$ & 1 & $2 \%$ \\
\hline 7. & $\begin{array}{l}\begin{array}{l}\text { Petugas memberikan perhatian terhadap } \\
\text { keluhan pasien }\end{array} \\
\end{array}$ & 42 & $100 \%$ & - & - \\
\hline 8. & $\begin{array}{l}\text { Petugas memberikan pelayanan } \\
\text { semua pasien tanpa memandang } \\
\text { social. }\end{array}$ & 42 & $100 \%$ & - & - \\
\hline 9. & $\begin{array}{l}\text { pasien merasa nyaman selama menunggu } \\
\text { obat. }\end{array}$ & 39 & $93 \%$ & 3 & $7 \%$ \\
\hline 10 & Kecepatan pelayanan obat. & 38 & $90 \%$ & 4 & $10 \%$ \\
\hline 11. & Obat yang tersedia dengan lengkap. & 31 & $74 \%$ & 11 & $26 \%$ \\
\hline 12. & $\begin{array}{l}\text { Petugas melayani dengan ramah dan } \\
\text { tersenyum. }\end{array}$ & 39 & $93 \%$ & 3 & $7 \%$ \\
\hline 13 & Apotek terlihat bersih dan rapi. & 40 & $95 \%$ & 2 & $5 \%$ \\
\hline
\end{tabular}


Gambaran tingkat kepuasan pasien terhadap pelayanan informasi obat Di Apotek Rawat Jalan RSUD Labuang Baji Makassar

\begin{tabular}{|c|l|c|c|c|c|}
\hline 14 & $\begin{array}{l}\text { Kelengkapan,kesiapan dan kebersian alat-alat } \\
\text { yang di pakai }\end{array}$ & 40 & $95 \%$ & 2 & $5 \%$ \\
\hline 15 & $\begin{array}{l}\text { Petugas apotek berpakaian yang bersih dan } \\
\text { rapih. }\end{array}$ & 41 & $98 \%$ & 1 & $\mathbf{2 \%}$ \\
\hline \multicolumn{2}{|c|}{ Rata-rata } & $\mathbf{4 0}$ & $\mathbf{9 4 , 6 \%}$ & $\mathbf{2}$ & $\mathbf{5 , 4 \%}$ \\
\hline
\end{tabular}

Sumber : Data primer 2015

Dari tabel Hasil kuesioner diatas dapat diketahui bahwa secara keseluruhan sebagian besar pasien menyatakan puas sebanyak 40 orang pasien (94,6\%).

\section{PEMBAHASAN}

Harapan masyarakat sekarang apabila berobat di pelayanan kesehatan, selain mengharapkan lebih dari sekedar suatu pengobatan yang tepat, juga mereka ingin merasakan kepuasan dalam hal pelayanan petugas yang profesional, ramah, ikhlas, bermutu dan antusias, termasuk pelayanan informasi obat.

Dalam beberapa literatur disebutkan bahwa terdapat lima determinan kualitas jasa yang dapat dirincikan sebagai berikut : (a.) Keandalan (reliability) adalah kemampuan untuk melakukan pelayanasn yang dijanjikan secara akurat dan terpercaya, (b.) Keresponsifan (responsiveness) adalah kesediaan untuk membantu konsumen dan menyediakan layanan yang dijanjikan, (c.) Keyakinan (assurance) adalah pengetahuan dan perilaku karyawan serta, kemampuan untuk menginspirasikan kepercayaan dan keyakinan, (d.) Empati (emphaty) adalah syarat untuk peduli, memberi perhatian pribadi bagi pelanggan, dan (e.) Berwujud (tangibels) adalah fasilitas fisik, peralatan, dan penampilan dari personil.

Dalam penelitian ini untuk mengukur tingkat kepuasan pasien di apotek rawat jalan di instalasi farmasi RSUD Labuang Baji Makassar, dikumpulkan informasi dengan cara dibagikan angket kepada pasien di apotek rawat jalan pada Bulan juli 2015. Angket yang dibagikan dalam bentuk kuisioner, responden cukup mencontreng pilihan yang ada pada lembar kuisioner yang dibagikan. Pilihan responden dibagi dalam 2 kategori yaitu puas dan tidak puas.

Pada penelitian yang di lakukan di apotek rawat jalan instalasi farmasi RSUD Labuang Baji Makassar didapatkan sebagian besar responden berusia 50 tahun keatas dan berpendidikan perguruan tinggi sejumlah 22 Orang pasien (52,5\%) dan untuk jenis kelamin sebagian besar responden berjenis kelamin 
Gambaran tingkat kepuasan pasien terhadap pelayanan informasi obat Di Apotek Rawat Jalan RSUD Labuang Baji Makassar

perempuaan sebanyak 25 orang pasien (60\%). Sementara untuk pekerjaan sebagian besar responden adalah bekerja sebagai ibu rumah tanggga sebanyak 15 orang pasien (36\%).

Tingkat pendidikan responden sebagian besar berpendidikan perguruan tinggi mempengaruhi pemahaman responden terhadap kuesioner yang diberikan. Selain itu, tingkat pendidikan juga berpengaruh cara pasien mengkategorikan kepuasannya terhadap pelayanan informasi obat di apotek rawat jalan RSUD Labuang Baji Makassar.pekerjaan juga dapat memberikan pengaruh terhadap resepsi responden yang bekerja dengan tingkat pendidikan perguruan tinggi mempunyai keinginan untuk mendapatkan pelayanan kesehatan yang lebih dan bermutu.

Tingkat kepuasan pasien terhadap pelayanan informasi obat di tinjau dari dimensi ketanggapan

Dari tabel diatas pada dimensi daya tanggap dapat di ketahui bahwa jumlah responden menyatakan puas sebanyak 41 orang pasien (98\%), sedangkan jawaban tidak puas sebanyak 1 Orang pasien (2\%), dengan pelayanan informasi obat di apotek rawat jalan RSUD Labuang Baji Makassar.

Melihat tingkat kepuasan pada dimensi ini tinggi dapat dikatakan bahwa pasien dapat mempercayai petugas dalam memberikan pelayanan kesehatan. walaupun yang tidak puas relative sedikit namum saja tetap penanganan bagi pelayanan yang dirasa pasien belum puas. Pentingnya memberikan informasi yang jelas tentang penyakitnya kepada pasien juga akan mempengaruhi kepuasan pasien terhadap kesehatan. Karna kepuasan pasien akan tercapai apabila diperoleh hasil optimal bagi pasien dalam pelayanan kesehatan dengan memperhatikan kemampuan pasien dan keluarga. Perhatian antara kebutuhan pasien tercapai keseimbangan sebaik-baiknya antara rasa puas dan tidak puas.

Tingkat kepuasan pasien terhadap pelayanan informasi obat ditinjau dari dimensi jaminan

Dari 42 responden yang diteliti untuk dimensi jaminan dapat di ketahui bahwa jumlah responden sebagian besar merasa puas dengan jaminan yang di berikan apotek terhadap pelayanan informasi obat sebanyak 40 orang pasien (96\%). dan sisanya menyatakan tidak puas sebanyak 2 orang pasien (4\%). 
Gambaran tingkat kepuasan pasien terhadap pelayanan informasi obat Di Apotek Rawat Jalan RSUD Labuang Baji Makassar

Pentingnya bagi instalasi farmasi rumah sakit untuk memberikan jaminan yang baik kepada pasien terhadap pelayanannya. Ketidakhatihatian petugas apotek dapat memberikan dampak yang fatal bagi pasien. Dari peran pihak rumah sakit dengan memberikan obat yang tepat sesuai dengan kebutuhan pasien. Pemberian informasi tentang indikasi, cara pakai, dan efek samping obat juga ikut memberikan andil dalam meningkatkan kepuasan pasien. Oleh karena itu petugas harus memiliki pengetahuan yang cukup tentang obat-obatan. Informasi yang salah akan menjadi pemicu terjadinya medication error pada pasien.

Tingkat kepuasan pasien terhadap pelayanan informasi obat di tinjau dari dimensi empaty atau kepedulian.

Dari 42 responden yang diteliti untuk dimensi kepedulian didapatkan jumlah responden yang menyatakan jawaban puas sebanyak 41 orang pasien (98\%), sementara jumlah responden yang menyatakan jawaban tidak puas sebayak 1 orang pasien $(2 \%)$.

Kepedulian dari para pemberi pelayanan kesehatan sangat berpengaruh besar dengan tingkat kepuasan pasien. Dari 42 responden dari setengahnya menyatakan puas dengan dimensi kepuasan empathy (kepedulian). Hal ini disebabkan antara lain oleh tingginya tingkat kepedulian para pemberi pelayanan kesehatan. Khususnya di apotek rawat jalan RSUD Labuang Baji Makassar yang tanpa memandang setatus sosial pasien dengan memberikan pelayanan kesehatan dengan semaksimal mungkin

\section{Tingkat kepuasan pasien terhadap} pelayanan informasi obat ditinjau dari dimensi keandalan

Dari 42 responden yang diteliti pada dimensi dapat di ketahui bahwa secara keseluruhan dari 42 responden yang diteliti, jumlah responden yang menyatakan jawaban puas sebanyak 36 orang pasien (86\%), yang menyatakan tidak puas sebanyak 6 orang pasien (14\%) terhadap pelayanan informasi obat dilihat dari dimensi keandalan.

Banyaknya pasien yang merasa puas dengan dimensi reabiliti (keandalan) mencerminkan bahwa petugas kesehatan di instalasi farmasi RSUD Labuang Baji Makasaar dan terampil dalm memberikan keterampilan dalam bidang kesehatan yang lebih teliti. 
Gambaran tingkat kepuasan pasien terhadap pelayanan informasi obat Di Apotek Rawat Jalan RSUD Labuang Baji Makassar

Tingkat kepuasan pasien terhadap pelayanan informasi obat ditinjaau dari dimensi wujud nyata

Dari 42 data yang diteliti pada dimensi wujud nyata jumlah responden yang menyatakan jawaban puas sebanyak 40 orang pasien (96\%), serta jumlah jawaban yang menyatakan tidak puas sebanyak 2 orang pasien (4\%).

Ketersediaan fasilitas yang menunjang dan sesuai dengan kebutuhan pasien, penampilan petugas yang menyakinkan tidak adanya perbedaan dalam pemberian pelayanan serta lingkungan yang nyaman dan bersih membuat pasien merasa nyaman dalam menerima pelayanan sehingga kebutuhan mereka dapat terpenuhi yang pada ahirnya menimbulkan kepuasan pada pasien.

\section{KESIMPULAN}

Berdasarkan hasil penelitian dan pembahasan, maka dapat di simpulkan bahwa tingkat kepuasan pasien terhadap pelayanan informasi obat di apotek rawat jalan RSUD Labuang Baji Makassar terhadap 42 responden, maka dapat ditarik beberapa kesimpulan sebagai berikut:

1. Pada dimensi responsiveness/ daya tanggap, 41 orang pasien (98\%) merasa puas, dan 1 orang pasien (2\%) menyatakan tidak puas.

2. Pada dimensi assurance/ jaminan, 40 orang pasien $(96 \%)$ merasa puas, dan 2 orang pasien (4\%) menyatakan tidak puas.

3. Pada dimensi empathy/ kepedulian, 41 orang pasien (98\%) merasa puas, dan 2 orang pasien (2\%) menyatakan tidak puas.

4. Pada dimensi reability/keandalan, 36 orang pasien (86\%) merasa puas, dan 6 Orang pasien (14\%) menyatakan tidak puas.

5. Pada dimensi tangibles/ wujud nyata, 40 orang pasien (96\%) merasa puas, dan 2 orang pasien (4\%) menyatakan tidak puas.

Sehingga dapat disimpulkan hasil kuesioner gambaran tingkat kepuasan pasien terhadap pelayanan informasi obat di apotek rawat jalan RSUD Labuang Baji Makassar sebagian besar responden menyatakan puas sebanyak 40 orang pasien $(94,6 \%)$, dan sisanya sebanyak 2 orang pasien $(6,4 \%)$ menyatakan tidak puas dengan pelayanan informasi obat di RSUD Labuang Baji Makassar.

\section{DAFTAR PUSTAKA}

Anonim. 2008, Peranan Farmasis Menunju Indonesia Sehat 2010 http://www.informasi obat. com. Diakses Juli 2015 
Gambaran tingkat kepuasan pasien terhadap pelayanan informasi obat Di Apotek Rawat Jalan RSUD Labuang Baji Makassar

Harianto dkk.,2005," kepuasan pasien terhadap pelayanan di apotek," Departemen Farmasi FMIPA-UI; Jakarta

Ikasari, N.H., 2008, Perbedaan Tingkat Kepuasan Pemberian Informasi Obat Antara Apotek Rawat Jalan dengan Apotek Rawat Inap Instalasi Farmasi Rumah
Sakit Ortopedi. Prof. Dr. $R$. Soeharso Surakarta," Skripsi Fak. Farmasi Unismuh, Surakarta

Lidya.p. Manurung. 2010," Analisi tinkat kepuasan pasien rawat jalan terhadap terhadap pelayanan instalasi 